\title{
Avaliação da rotulagem de leites UHT comercializados no Vale do Taquari-RS
}

REVISTA ELETRÔNICA CIENTIIFICA DA UERGS

Jeferson Aloísio Ströher

Universidade Estadual do Rio Grande do Sul (UERGS).

E-mail: jeferson.stroher@hotmail.com, http://lattes.cnpq.br/707338I50226I652

Marta Regina dos Santos Nunes

Universidade Estadual do Rio Grande do Sul (UERGS).

E-mail: marta-nunes@uergs.edu.br, http://lattes.cnpq.br/269|46565I685097

Luís Carlos Oliveira dos Santos Júnior

Universidade Estadual do Rio Grande do Sul (UERGS).

E-mail: luisc.oliveirajr@gmail.com, http://lattes.cnpq.br/40I6I57732519740

ISSN 2448-0479 Submetido em: 06 out. 2020. Aceito: 28 fev. 202I. DOI: http://dx.doi.org/10.21674/2448-0479.72.186-195

\section{Resumo}

A legislação brasileira estipula que os rótulos de alimentos devem conter informações obrigatórias e essenciais para os consumidores conhecerem a procedência e a composição do produto em questão. Nesse sentido, os órgãos de fiscalização estabeleceram normas e leis específicas sobre as informações que devem estar presentes nos rótulos das embalagens para padronizá-los e garantir que os mesmos não causem engano, dúvidas ou danos ao consumidor. O objetivo deste trabalho foi verificar a rotulagem de embalagens de leite UHT segundo as normas vigentes. Foram avaliados os rótulos das embalagens de nove marcas de leite integral e desnatado comercializados no Vale do Taquari (RS). Os resultados obtidos permitiram concluir que grande parte dos rótulos analisados apresentaram não conformidades com a legislação brasileira e, devido a isso, somente estariam aptos para comercialização mediante ajustes em relação à legislação vigente.

Palavras-chave: leite UHT; rotulagem; legislação; embalagem.

\section{Abstract}

\section{Verification of labels of milk commercialized at grocery stores and supermarkets in Vale do Taquari - RS}

Brazilian law defines that food labels must contain mandatory and essential information to inform consumers the origin and the composition of the product in question. Therefore, regulating agencies have established rules and laws with the aim to standardize information on packaging labels, as well as ensure that they do not confuse, cause doubt or damage to the consumer. The aim of this study was to verify if the labeling of UHT milk follows current regulations. The packaging labels of nine brands of both whole and skim milk sold Vale do Taquari - RS were evaluated. Results of our analysis lead to the conclusion that most of the labels present noncompliance with current rules and legislation. Hence, they would only be suitable for commercialization after adjustments obeying Brazilian legislation.

Keywords: UHT milk; labeling; legislation; package. 


\section{Resumen}

\section{Análisis del etiquetado de la leche UHT comercializados en el Valle del Taquari-RS}

La legislación brasileña estipula que las etiquetas de los alimentos deben contener informaciones obligatorias y esenciales para que los consumidores conozcan el origen y la composición del producto en cuestión. En ese sentido, las agencias de inspección han establecido reglas y leyes específicas acerca de las informaciones que deben estar presentes en las etiquetas de los empaques para que estén estandarizados, así como para asegurar que no engañen, siembren dudas o causen daño al consumidor. El objetivo de este trabajo fue verificar las etiquetas de los envases de leche UHT según las normativas vigentes. Fueron evaluadas las etiquetas de empaque de nueve marcas de leche integral y desnatada comercializados en el Valle del Taquari (Vale do Taquari - RS). Los resultados obtenidos permitieron concluir que gran parte de las etiquetas analizadas no presentaban inconformidades con la legislación brasileña y, por ello, solamente estarían aptas para la comercialización delante ajustes en conformidad con la legislación vigente.

Palabras clave: leche UHT; etiquetado; legislación; el empaquetado.

\section{Introdução}

Os rótulos são elementos de comunicação entre produtos e consumidores; logo, tem como finalidade auxiliá-los na decisão de compra, aumentando a eficiência do mercado e o bem-estar da população. Cabe ressaltar que, no caso de produtos alimentícios, o fato da rotulagem ser obrigatória, não significa que os consumidores a utilizem como uma ferramenta para a escolha dos alimentos que devem compor sua dieta habitual e, assim, reduzir os excessos alimentares (excesso de sódio, açúcares, gordura, etc.) e os danos ocasionados à saúde (MACHADO et al., 2006), sendo que estes excessos podem ocasionar doenças como hipertensão, diabetes, colesterol entre outras.

O rótulo ou rotulagem consiste em toda inscrição, legenda, imagem e matéria descritiva ou gráfica que esteja escrita, impressa, estampada, gravada, gravada em relevo, litografada ou colada sobre a embalagem ou contentores do produto destinado ao comércio, com vistas à identificação. Existem vários artigos na legislação brasileira que definem a maneira como o rótulo deve informar o consumidor acerca do produto alimentício comercializado, e isto deve ser rigorosamente controlado pela indústria responsável pelo processamento do alimento (BRASIL, 20 I7a). São eles: Portaria $n^{\circ} .27$ (BRASIL, I998); Portaria $n^{\circ} .259$ (BRASIL, 2002); Portaria $n^{\circ}$. I57, (INMETRO, 2002); RDC n. 360 (BRASIL, 2003a); RDC n. 359 (BRASIL, 2003b), Lei $n^{\circ} .10 .674$ (BRASIL, 2003c); Instrução Normativa (IN) n. 22 (BRASIL, 2009); RDC n. 163 (BRASIL, 2006a); Lei $n^{\circ}$. II 265 (BRASIL, 2006b); RDC nº 26 (BRASIL, 20I5) e a RDC n. I 36 (BRASIL, 20 I 7b); Decreto n. 10.468 de 18 de agosto de 2020 (BRASIL, 2020a).

Uma das normativas mais importantes relacionadas à rotulagem de alimentos de origem animal, a qual se inclui o leite UHT, está descrita no Regulamento da Inspeção Industrial e Sanitária de Produtos de Origem Animal - RIISPOA, onde se relata que:

\footnotetext{
Os estabelecimentos só podem expedir ou comercializar matérias primas e produtos de origem animal registrados pelo Departamento de Inspeção de Produtos de Origem Animal (DIPOA) e identificados por meio de rótulos, dispostos em local visível, quando destinados diretamente ao consumidor ou quando enviados a outros estabelecimentos onde serão processados (BRASIL, 2017a).
}

Segundo as normas, a rotulagem necessita ser resistente às condições de armazenamento e de transporte e, quando em contato direto com o produto, o material utilizado em sua confecção deve ser previamente autorizado pelo órgão regulador da saúde. A norma também indica que as informações presentes nos rótulos devem estar visíveis, com caracteres legíveis, em cor contrastante com o fundo e indeléveis, assim como apresentar identificação que permita a rastreabilidade dos produtos (BRASIL, 2020b).

No rótulo de leite UHT e produtos de origem animal em geral é vedada a presença de representações gráficas que possam transmitir informações falsas, incorretas, insuficientes ou que possam, direta ou indiretamente, induzir o consumidor a equívoco, erro, confusão ou engano em relação às características gerais do 
produto, uma vez que a lei proíbe fabricar, expedir ou distribuir produtos de origem animal com rotulagem falsificada (BRASIL, 2020b). No Brasil, os órgãos federais como Agência Nacional de Vigilância Sanitária (ANVISA), Ministério da Agricultura Pecuária e Abastecimento (MAPA) e pelo Instituto Nacional de Metrologia, Normalização e Qualidade Industrial (INMETRO) são responsáveis pela obrigatoriedade e regulamentação pelas legislações quanto à rotulagem dos alimentos embalados, como o leite UHT (EMBRAPA, 2020). A produção de leite UHT segue a rotulagem nutricional definida pela Resolução da Diretoria Colegiada RDC $n^{\circ} .360$ (BRASIL, 2003a) que expõe sobre "toda descrição destinada a informar ao consumidor sobre as propriedades nutricionais de um alimento", sendo aplicada aos alimentos produzidos e comercializados, qualquer que seja sua origem, embalados na ausência do cliente e prontos para serem comercializados.

Tendo em vista a relevância da rotulagem como garantia de veracidade das informações expostas, e a sua utilização visando prevenir o consumo indevido de alimentos, o objetivo geral deste trabalho foi avaliar a rotulagem presente nas embalagens de leites UHT (integral e desnatado) de nove marcas comercializadas em estabelecimentos no Vale do Taquari, região Central do Estado do Rio Grande do Sul, quanto às conformidades e não conformidades de acordo com a legislação brasileira.

\section{Metodologia}

A avaliação foi realizada verificando se havia conformidade ou não conformidade com a legislação brasileira na rotulagem do leite UHT produzido e comercializado na Região do Vale do Taquari-RS. Para isso, foram coletadas 18 caixas de leite UHT de I L (um litro) de nove marcas diferentes, sendo que a cada marca selecionada, foram coletadas uma amostra de leite integral e uma amostra de leite desnatado. Cada amostra foi codificada de I (um) a 9 (nove), sendo acrescentadas as letras "l" para o leite integral e "D" para o leite desnatado. O conteúdo para avaliação foi adquirido, em média, 15 dias a partir da data de fabricação.

As amostras foram adquiridas durante o ano de 2019 em estabelecimentos comerciais de quatro municípios da região estudada. $O$ conteúdo para avaliação foi adquirido, em média, 15 dias a partir da data de fabricação. $\mathrm{O}$ arcabouço legal utilizado no estudo está descrito na Tabela I.

Tabela I - Legislações utilizadas na avaliação da rotulagem do leite UHT produzidos no Brasil, de acordo com seu ano de publicação.

\begin{tabular}{|c|c|c|}
\hline $\begin{array}{c}\text { Ano da } \\
\text { publicação }\end{array}$ & Legislação & Regulamentação \\
\hline 1998 & Portaria $n^{\circ} .27$ & Informação Nutricional Complementar \\
\hline 2002 & RDC n. 259 & Regulamento Técnico sobre Rotulagem de Alimentos Embalados \\
\hline 2002 & $\begin{array}{l}\text { Portaria INMETRO } \mathrm{n}^{\circ} \text {. } \\
\qquad 157\end{array}$ & $\begin{array}{l}\text { Regulamento Técnico Metrológico. Instituto Nacional de Metrologia, Normalização } \\
\text { e Qualidade Industrial (INMETRO) }\end{array}$ \\
\hline 2003 & $\operatorname{RDC} n^{\circ} .360$ & Trata das informações nutricionais obrigatórias \\
\hline 2003 & RDC n. 359 & $\begin{array}{l}\text { Decreta que o tamanho da porção deve ser determinado de acordo com uma } \\
\text { alimentação diária de } 2000 \text { kcal (variação de } 30 \% \text { para mais ou menos). }\end{array}$ \\
\hline 2003 & Lei $n^{\circ} .10 .674$ & $\begin{array}{l}\text { Rotulagem de Alimentos e bebidas embalados com a declaração que contenham } \\
\text { glúten ou não contenham glúten }\end{array}$ \\
\hline 2005 & $\begin{array}{l}\text { Instrução Normativa } \\
n^{\circ} .22\end{array}$ & $\begin{array}{l}\left.\text { Rotulagem geral de alimentos embalados (complementa RDC N } N^{\circ} 359 / 2003\right) \text {, RDC } \\
n^{\circ} 360 / 2003 \text { ) }\end{array}$ \\
\hline 2006 & RDC n०. 163 & Rotulagem geral de alimentos embalados \\
\hline 2015 & $\operatorname{RDC} n^{\circ} .26$ & Rotulagem de Alimentos que causam alergias alimentares \\
\hline 2017 & $\operatorname{RDC} n^{\circ} .136$ & Rotulagem de Alimentos que contenham lactose em sua composição \\
\hline
\end{tabular}

Fonte: Autores (2020)

Para fins de avaliação da Portaria $\mathrm{n}^{\circ}$. 27, foram considerados somente o item 3.2.I (apresentação da informação nutricional complementar por $100 \mathrm{~g}$ ou $100 \mathrm{~mL}$ ) e o item 4.2 .2 (utilização da expressão "aumentado") que decreta como a informação deve ser expressa e qual expressão deve ser utilizada quando for cumprido o atributo de "aumentado". Os demais itens descritos nesta portaria não foram avaliados, pois não se aplicaram à metodologia deste trabalho (BRASIL, 1998). 


\section{Resultados e Discussão}

\section{Avaliação das rotulagens}

As nove marcas avaliadas neste trabalho apresentaram conformidade em diversos itens relacionados à legislação brasileira. Todas foram inspecionadas pelo Sistema de Inspeção Federal (SIF) do Ministério da Agricultura e Pecuária e Abastecimento (MAPA), sendo que este selo é o mais comum para as empresas de leite UHT, pois permite a comercialização de produtos em todo o território brasileiro. No rótulo, este selo geralmente situa-se no canto lateral esquerdo nas embalagens de leite UHT.

Das amostras de leite UHT avaliadas, duas marcas não são produzidas em suas unidades fabris, sendo o serviço de envase terceirizado. Tal informação consta na rotulagem, conforme preconizado pela legislação (BRASIL, 2020b). Além disso, duas marcas pertencem ao mesmo grupo empresarial, ou seja, são envasadas na mesma unidade fabril e, por isso, a unidade fabricante do produto foi identificada na rotulagem de forma clara, por meio de texto informativo, código ou outra forma, assegurando a clareza da informação, conforme dispõe a legislação (BRASIL, 2020b).

Foi verificado que uma das marcas de leite UHT desnatado avaliadas neste trabalho possuía rotulagem nutricional complementar, o que segundo a Portaria $\mathrm{n}^{\circ} .27$ (BRASIL, 1998) é um item opcional. Na parte frontal da rotulagem desta mesma marca, consta o termo "light" e logo abaixo "** como todo o leite desnatado". Já na parte lateral da rotulagem consta a frase: "Comparação realizada entre o leite UHT Integral (nome da marca própria) e o leite UHT Desnatado (nome da marca própria). Reduzido em $83 \%$ de gorduras totais". Todo o leite desnatado tem como característica conter o teor de gordura em no máximo 0,5\%. O item 4.2.I da Portaria $n^{\circ} .27$ descreve que o termo "light", "lite", "leve" ou "reduzido" pode ser utilizado quando for cumprido o atributo reduzido (BRASIL, 1998). Porém, foi identificada uma não conformidade na comparação feita entre o leite UHT integral e o desnatado, uma vez que a Portaria $n^{\circ} .27$ (BRASIL, 1998) permite comparar apenas versões de leite UHT desnatado entre fabricantes diferentes. Costa (20I4) e Barros (2003), em pesquisas semelhantes, apresentaram situações similares a este trabalho, em que os mesmos atributos citados acima foram destacados.

Referente à Portaria $\mathrm{n}^{\circ}$. I57 (INMETRO, 2002), todas as marcas se apresentaram de acordo com a indicação quantitativa do conteúdo líquido do sistema internacional de unidades (IL) e possuem altura mínima dos algarismos e símbolos da unidade de medida e sua largura dos caracteres e são alfas numéricos. É considerado fraude constar na rotulagem uma quantidade de produto distinta do presente no alimento, sendo geralmente menor que o informado.

Quanto à RDC n 360 (BRASIL, 2003a), que se refere ao tamanho da porção a ser tomada como referência, as capacidades e dimensões das medidas caseiras e a tolerância de variação do valor estabelecido para a porção do alimento, todas as marcas atenderam aos itens estabelecidos. Esta mesma RDC também estabelece quais são as informações nutricionais obrigatórias que devem constar no rótulo. Neste quesito, todas as marcas estavam em conformidade; sendo este, um item de grande relevância para o consumidor, pois assim é possível informar-se sobre a quantidade média do alimento que pode ser consumida, controlando e monitorando a ingestão calórica, uma vez que muitas pessoas apresentam algum tipo de intolerância ou enfermidade, e necessitam regular o consumo de certos tipos e fontes de alimentos.

Nas amostras avaliadas no presente estudo, foram observadas 100\% de conformidade para a apresentação da porção nos rótulos dos leites UHT, sendo que a porção é a quantidade do alimento utilizada como referência para o cálculo nutricional e todas as informações nutricionais indicadas no rótulo valem apenas para a porção indicada pelo fabricante do produto e não para o seu conteúdo total.

\section{Avaliação das tabelas nutricionais dos rótulos de leite UHT analisados}

A RDC n. 360 (BRASIL, 2003a) é extremamente importante, pois apresenta a obrigatoriedade da informação nutricional que deverá constar nos rótulos, permitindo o acesso do conteúdo informativo por parte do consumidor. Todas as marcas atenderam as especificações desta legislação.

Os resultados das nove marcas analisadas foram satisfatórios; pois cumprem a Lei $n^{\circ}$. 10.674 (BRASIL, 2003c), que afirma que todas as marcas devem ter em seus rótulos a frase "contém glúten" ou "não contém 
glúten". A presente informação é importante para alertar os consumidores que apresentam intolerância ao glúten ou são portadores de doença celíaca. Além disso, uma problemática em relação à rotulagem de alimentos no Brasil foi observada em relação aos produtos alimentícios "diet" e "light", pois os pesquisadores verificaram a ausência da advertência sobre a presença de glúten em 5,3\% dos produtos (CÂMARA et al., 2008). Por outro lado, Oliveira et al. (2019) ao avaliarem cinco marcas de leite UHT integral e desnatado, totalizando trinta amostras adquiridas no varejo da cidade de Sete Lagoas (MG), no ano de 2018, apresentaram o mesmo resultado do presente estudo, estando todas as amostras de acordo com a legislação.

A RDC n․ 359 (BRASIL, 2003b) é responsável pela regulamentação de indicação do tamanho da porção. Esta indicação deve ser determinada de acordo com uma alimentação diária de $2000 \mathrm{kcal}$, sendo aceitável uma variação de $30 \%$, para mais ou para menos, em relação ao valor estabelecido para a porção do alimento. Foram encontradas conformidades em todas as marcas analisadas referente à rotulagem nutricional, sendo que em todas as marcas utilizou-se a porção de $200 \mathrm{~mL}$ para representar I (um) copo, ou seja, uma medida caseira. A informação da porção descrita na rotulagem nutricional é relevante para o consumidor apropriar-se desse conhecimento com o objetivo de controlar e monitorar a sua ingestão calórica e nutricional (CAMARA et al., 20I4).

Quanto às tabelas nutricionais dos leites integrais e desnatados, todas as marcas atendem o que preconiza a legislação brasileira (BRASIL, 2003a).

Foi observado que os principais fatores que podem resultar em diferenças entre os dados avaliados são: a descrição incorreta de alimentos e/ou fontes de valores nutricionais; uma amostragem inadequada; a utilização de métodos analíticos impróprios e inconsistência na terminologia utilizada para expressar certos nutrientes; e a variabilidade resultante de fatores genéticos, ambientais, de preparo e processamento.

Todas as amostras apresentaram o termo valor energético e um percentual (\%) de valor diário (VD), baseado em uma dieta de $2.000 \mathrm{kcal}$ ou $8.400 \mathrm{~kJ}$, conforme preconiza a RDC $\mathrm{n}^{\circ} .360$ (BRASIL, 2003a). O teor de cálcio e sódio, mesmo não sendo obrigatórios, estavam presentes na informação nutricional de todas as diferentes marcas de leite UHT integral e desnatado, e isto pode ser importante, uma vez que estes minerais são essenciais para crescimento e manutenção de funções vitais do nosso organismo. A quantificação correta nos rótulos de leite UHT é importante para monitoramento tanto das pessoas saudáveis quanto para aquelas que possuem restrições de nutrientes na dieta.

Em relação à IN nº 22 (BRASIL, 2009), todas as marcas apresentaram conformidades com esta legislação. Em nenhuma das amostras analisadas neste trabalho consta na lista de ingredientes o termo "leite de vaca", constando apenas "leite integral" ou "desnatado", mesma constatação de Gibson (1990 apud Giesel 2009) que analisou a denominação de venda de dez rótulos de leite UHT integral. É importante a padronização da nomenclatura dos leites para não induzir o consumidor ao erro na compra do produto. Esta mesma IN n 22 explana que, com exceção de produtos de origem animal com um único ingrediente, deve constar no rótulo uma lista de ingredientes, os aditivos e a sua função, estando também conforme todas as marcas estudadas neste trabalho (BRASIL, 2009).

As marcas apresentaram conformidade com o artigo II, inciso $\mathrm{I}^{\circ}$. da Lei $\mathrm{n}^{\circ}$. II.265 (BRASIL, 2006b) que diz que os rótulos de fórmula infantil, de seguimento para crianças de primeira infância, deverão exibir no painel principal, de forma legível e de fácil visualização, o seguinte destaque: "*AVISO IMPORTANTE: Este produto não deve ser usado para alimentar crianças menores de I (um) ano de idade". O aleitamento materno evita infecções e alergias e é recomendado até os 2 (dois) anos de idade ou mais. Diferentemente deste trabalho, Gibson (1990) apud Giesel, (2009) verificou que $90 \%$ dos rótulos analisados não apresentaram corretamente a frase de advertência obrigatória, além de ser utilizada uma letra com tamanho inferior às demais letras utilizadas no rótulo. A diferença entre o resultado encontrado no presente trabalho em relação a um trabalho do ano de 2009, pode ser atribuída as diversas campanhas incentivando o aleitamento materno da última década.

Já em relação ao capítulo III, item I, da Lei $\mathrm{n}^{\circ}$. II.265, em cinco marcas foram encontradas não conformidades (integral e desnatado), pois as mesmas apresentavam desenhos ou figuras que configuram apelo à compra do produto. Esta lei relata a proibição da utilização de fotos, desenhos ou outras representações gráficas, que não sejam aquelas necessárias para ilustrar métodos de preparação ou uso do produto ou rótulos de fórmula infantil para lactentes. A utilização de representação gráfica é considerada apelo e estes desenhos induzem crianças à compra do produto (BRASIL, 2006b).

Também houve irregularidades em quatro marcas com relação ao item $\mathrm{V}$, da Lei $\mathrm{n}^{\circ}$. 11.265 (BRASIL, 2006b), no qual é exposto que os rótulos não devem utilizar informações que possam induzir o uso dos produ- 
tos em virtude de falso conceito de vantagem ou segurança. Uma das marcas analisadas relaciona o consumo do produto a um código QR (Quick Response) e descreve uma suposta vantagem que estaria vinculada ao uso deste código para um rastreamento das análises realizadas no leite, desde o campo até o envase na indústria, mas conforme a lei citada, isto é proibido. Outra marca apresenta em seu rótulo a quantidade de análises que são realizadas no leite até ser envasado, sendo que, perante a lei, todas as marcas devem realizar os procedimentos descritos a fim de assegurar a qualidade do leite e atendimento às exigências brasileiras. $\mathrm{Na}$ área frontal da embalagem da mesma marca, observou-se outra irregularidade, a inscrição "Sem conservantes: como todo o leite UHT", novamente relacionando vantagens em um procedimento regular de processamento.

Estas não conformidades apresentadas nas rotulagens de leites UHT, podem configurar os mesmos como produtos falsificados, sendo que a presença de dizeres, gravuras ou qualquer expressão que induza o consumidor a erro ou confusão quanto à origem, à natureza ou à qualidade do produto ou the atribua qualidade terapêutica ou medicamentosa, não é permitida (ANVISA, 2017).

Em outra marca, foi encontrada a frase: "Fonte de Cálcio*”, com a descrição: “*como todo o leite." O cálcio é um mineral essencial para o crescimento e manutenção do nosso organismo, principalmente para as crianças em fase de desenvolvimento, mas a informação na rotulagem sobre a presença de um componente naturalmente presente no alimento, pode induzir à compra do produto entre os consumidores que desconhecerem a composição. O artigo do RIISPOA (BRASIL, 20I7a) preconiza que os rótulos dos produtos de origem animal não podem destacar a presença ou ausência de componentes que sejam intrínsecos ou próprios de produtos de igual natureza, exceto nos casos previstos em legislação específica. O cálcio é um componente intrínseco ao leite e não deve, portanto, a sua presença aparecer em destaque como uma possível vantagem no consumo.

As nove marcas de leite avaliadas, atenderam devidamente a RDC n'. 26 (BRASIL, 20I5) sobre alergênicos. O resultado obtido é similar ao obtido por Morais et al. (2016) que em 2015 analisaram 31 rótulos de leite UHT de 19 marcas de leite UHT integral, semidesnatado e desnatado na cidade de Campina Grande (PB). Porém em duas marcas (integral e desnatado), além da frase sobre os alergênicos, continha a frase: "Pode conter soja". As alergias alimentares são reações adversas a uma resposta imunológica que ocorre em indivíduos que apresentam alguma sensibilidade ao consumir determinados tipos de alimento, podendo levar a óbito (BRASIL, 20I7b). Sendo assim, a melhor forma para evitar o consumo de alimentos que possuem algum tipo de alergênico é uma leitura cuidadosa dos rótulos dos produtos (PIERETTI et al., 2009).

Quanto aos artigos $3^{\circ}$. e $4^{\circ}$. da RDC $n^{\circ}$. 136 (BRASIL, 20I7b), foi observado em todas as marcas de leite UHT, a frase: "contém lactose", escrita imediatamente após ou abaixo da lista de ingredientes. Uma das marcas não atendeu ao requisito III desta RDC, relativo ao destaque da escrita em negrito. A intolerância à lactose ocorre quando o organismo é incapaz de produzir, ou apresenta baixa produção de lactase, a enzima responsável pela metabolização da lactose, que é o açúcar predominante do leite. E então ao ser ingerido, pode desencadear alguns efeitos adversos como: cólicas, flatulência, dor e diarreia osmótica (TÉO, 2002).

A legislação preconiza que cada empresa produtora de leite UHT seja responsável por definir a data de validade de seus produtos, informação impressa no rótulo. O número do lote, também impresso no rótulo, é importante para a rastreabilidade dos produtos fabricados pelas empresas, sendo que todas as marcas estavam conforme a legislação. Segundo o Decreto 10.468 (BRASIL, 2020a), o prazo de validade e a identificação do lote devem ser impressos, gravados ou declarados por meio de carimbo, conforme a natureza do envoltório, observadas as normas complementares. Com relação ao número do lote, foi observado que as empresas utilizaram letras e números, sendo mais recorrente o uso da letra $L$ (lote) acrescido de um número e a letra $S$ (silo), indicando o local, na indústria, em que o leite pasteurizado foi armazenado. Também foi verificada a presença de letras que indicam em qual máquina o produto foi envasado. No requisito hora do envase do produto, sete marcas somente utilizam a hora e o minuto e duas marcas utilizam hora, minuto e segundo. As marcas que apresentaram um detalhamento maior dos lotes de fabricação conferem ao produto disponibilizado no mercado, uma maior rastreabilidade. A rastreabilidade possibilita $\circ$ acompanhamento em todas as etapas da produção, do processamento dentro da unidade fabril até o consumidor final e isso configura uma preocupação cada vez maior do produtor e do consumidor.

Um dos pontos mais críticos encontrado ao longo deste trabalho, diz respeito à lista dos ingredientes contidos nos rótulos de leite UHT. Foi verificado que quatro marcas utilizaram a denominação "leite fluido" (acrescido da nomenclatura integral ou desnatado). Uma marca utilizou a denominação "leite pasteurizado" 
(integral ou desnatado) e outras quatro marcas utilizaram o termo "leite integral" ou "leite desnatado", simplesmente. Esta denominação do ingrediente leite na rotulagem deveria ser padronizada pelas empresas ou definida em legislação específica, para evitar dúvidas ou erro ao consumidor que, por muitas vezes, não sabe a diferença entre os termos utilizados.

A exemplo do que foi descrito por Miyoshi et al. (2016), encontrou-se no rótulo de uma marca de leite o ingrediente pirofosfato dissódico INS450i. Segundo o RTIQ (Regulamento Técnico de Identidade e Qualidade) do Leite UHT (BRASIL, 1997), o pirofosfato dissódico INS450i não consta na lista de aditivos permitidos para leite UHT, e sim, somente para produtos cárneos (BRASIL, 2006) e outros alimentos como estabilizante e fermento químico (BRASIL, 2008). Para a fabricação de leite UHT, somente os seguintes estabilizantes são permitidos: citrato de sódio, monofosfato de sódio, difosfato de sódio, trifosfato de sódio, separados ou em combinação, em uma quantidade não superior a $0,1 \mathrm{~g} / 100 \mathrm{~mL}$ expressos em $\mathrm{P}_{2} \mathrm{O}_{5}$ (BRASIL, 1997). Ainda que não exista norma específica indicando a sua proibição, tampouco há uma que autorize sua utilização enquanto estabilizante em leite UHT no Brasil. Sendo assim, o leite UHT que apresenta o pirofosfato dissódico em sua composição, pode ser considerado um produto adulterado e, portanto, que não está em conformidade com a legislação brasileira (BRASIL, 20I7a).

A informação do percentual de gordura do leite estava em conformidade em todas as marcas de leite UHT integral, sendo apresentado o valor de $3 \%$ de gordura na parte frontal da embalagem. Já em relação ao leite UHT desnatado existem divergências: duas marcas, por exemplo, não apresentaram referência quanto à quantidade de gordura do leite, uma marca descreve que a quantidade é de $0,5 \%$ em teor de gordura, outras marcas descrevem $0 \%$ (zero por cento) de gordura e, por fim, uma outra marca consta a frase: "Light como todo o leite desnatado", ou seja, não constando qualquer informação sobre o teor de gordura. E dentre as quatro marcas que descrevem o leite como $0 \%$ de gordura, uma delas complementa com a seguinte frase: todo o leite desnatado tem a característica de conter no máximo $0,5 \%$ de gorduras totais por porção. Tal afirmativa, pode induzir o consumidor ao equívoco na hora da compra do produto. A marca de leite UHT desnatado que descreve a palavra "light" na área central da rotulagem, complementa na lateral da embalagem: "característica conter o teor de gordura em no máximo 0,5\%", o que também pode causar dúvidas ao consumidor. O termo "light" é permitido em alimentos que possuem o atributo baixo para o conteúdo absoluto de nutrientes e ou valor energético (BRASIL, 1998).

Sete marcas atenderam parcialmente à legislação quando descrevem a porcentagem da gordura do leite UHT desnatado na rotulagem, porém é de suma importância a padronização destas informações na rotulagem. O RTIQ do leite UHT explana que a matéria gorda do leite UHT integral deverá ser de no mínimo 3,0\% e a do leite UHT desnatado de no máximo 0,5\% (BRASIL, 1997).

Os modos de conservação doméstica do leite descritos nas embalagens podem variar de acordo com cada fabricante. Há de se destacar uma frase encontrada em uma marca $\left(n^{\circ} .2\right)$ que recomenda que o leite não seja fervido pois, segundo o fabricante, alteraria seu valor nutritivo, o que torna a informação duvidosa. A mesma marca $\left(n^{\circ} .2\right)$ também informa que o leite não necessita de refrigeração, mas não esclarece se a informação está relacionada ao produto inviolado ou depois de aberto. Quanto às temperaturas de refrigeração do leite após aberto, verificamos valores entre $1{ }^{\circ} \mathrm{C} \mathrm{e} 2^{\circ} \mathrm{C}$, sendo que todos contêm a frase: "não precisa ferver este leite", exceto uma das marcas. Nos rótulos estudados, não foram encontradas menções honrosas recebidas pelas empresas e também não há expressões de qualidade do produto, conforme menciona a legislação (BRASIL, 2020a).

No dia 8 de outubro de 2020, entrou em vigor a RDC n. 429 da Anvisa (BRASIL, 2020b), sendo aprovada a nova legislação para rotulagem nutricional frontal e algumas mudanças na tabela nutricional. $O$ órgão estabeleceu um novo design de uma lupa para identificar o alto teor de três nutrientes, sendo eles os açúcares adicionados, as gorduras saturadas e o sódio, sendo que este símbolo deverá ser aplicado na frente do produto, na parte superior. Quanto às alterações na tabela de informação nutricional, ela passará a ter apenas letras pretas e fundo branco e passará a ser obrigatória a identificação de açúcares totais e adicionais, a declaração do valor energético e nutricional por $100 \mathrm{~g}$ ou $100 \mathrm{ml}$, a tabela também deverá ficar próxima da lista de ingredientes e em superfície contínua, não sendo aceitas quebras. Ela não poderá ser apresentada em áreas encobertas, locais deformados ou regiões de difícil visualização. Sendo estabelecido o prazo de doze meses para a adequação dos produtos que já se encontram no mercado na data de entrada em vigor desta resolução (BRASIL, 2020b). 


\section{Considerações finais}

A avaliação das rotulagens demonstrou que as nove marcas analisadas atendem à maior parte dos padrões estabelecidos pela legislação brasileira. Verificou-se, entretanto, não conformidades em cinco marcas quanto à Lei II 265 de 2006, sobre reproduções gráficas na rotulagem. A situação mais grave verificada diz respeito a uma marca que utilizou e descreveu no rótulo o uso de um estabilizante que não consta na lista dos insumos permitidos para leites UHT. Também foi verificada a importância da padronização da denominação para o ingrediente "leite", uma vez que esta se mostrou confusa, dada as diversas formas apresentadas neste trabalho, podendo acarretar em dúvidas ao consumidor.

Embora tenham sido constatadas diversas conformidades, a quantidade de rótulos de leite UHT não conformes com a legislação brasileira foi significativa. É de suma importância que as empresas atualizem as informações contidas nas rotulagens, a fim de se adequarem às legislações para não gerar dúvidas e não lesar os consumidores na hora da compra desses produtos.

É de suma importância a avaliação destas informações presentes nas embalagens, segundo o RIISPOA. A legislação apontada considera como produtos adulterados, aqueles que durante a manipulação ou no processo de elaboração tenham sido empregadas matérias-primas ou ingredientes impróprios ou que não atendam ao disposto no RTIQ, ou na formulação indicada no registro do produto.

Para sanar tais não conformidades, sugere-se que os órgãos de controle, como a ANVISA e o MAPA, sejam mais atuantes na fiscalização para o cumprimento das legislações vigentes, a fim de garantir que o consumidor adquira leites UHT com maior segurança e informação.

\section{Referências}

ANVISA. Perguntas e respostas: rotulagem de alimentos alergênicos. Brasil. 2017. Disponível em: https://alimentusconsultoria.com.br/perguntas-respostas-alergenicos-revisado/. Acesso em: ago. 2020.

BARROS, D. L. G. Avaliação da qualidade físico-química e análise da rotulagem de leites UHT integral, semidesnatado e desnatado comercializados em Brasília. 2003. 108 f. Dissertação (Mestrado em Nutrição Humana), Setor de Ciências da Saúde. Universidade de Brasília, Brasília - DF, 2003.

BRASIL. Legislação. Decreto $n^{\circ}$. 10.468, de 18 de agosto de 2020. Altera o Decreto $n^{\circ} .9 .013$, de 29 de março de 2017, que dispõem sobre o regulamento da inspeção industrial e sanitária de produtos de origem animal. 2020a. Disponível em: http://www.planalto.gov.br/ccivil_03/_ato2019-2022/2020/decreto/DI 0468.htm. Acesso em: ago. 2020.

BRASIL. Legislação. Instrução Normativa $\mathbf{n}^{\circ}$. 22, de 2 de junho de 2009. Regulamenta a embalagem, rotulagem e propaganda dos produtos destinados à alimentação animal. Disponível em: http://extranet.agricultura.gov.br/sislegisconsulta/consultarLegislacao.do?opera ao=visualizar\&id=20207. Acesso em: jun. 2020.

BRASIL. Legislação. Instrução Normativa $\mathrm{n}^{\circ}$. $5 \mathrm{I}$, de 29 de dezembro de 2006. Aprova o regulamento técnico Mercosul de atribuição aditivos, e seus limites das seguintes categorias de alimentos 8: Carne e Produtos. Disponível em: https://www.normasbrasil.com.br/norma/instrucaonormativa5 I 2006_76049.html >. Acesso em: jun. 2020.

BRASIL. Legislação. Lei $\mathbf{n}^{\circ}$. 10.674, de $\mathbf{1 6}$ de maio de 2003. Obriga a que os produtos alimentícios comercializados informem sobre a presença de glúten, como medida preventiva e de controle da doença celíaca. 2003c. Disponível em: http://www.anvisa.gov.br/legis/leis// 0674_03.htm. Acesso em: jun. 2020.

BRASIL. Legislação. Lei $n^{\circ}$. 11 .265, de 3 de janeiro de 2006. Regulamenta a comercialização de alimentos para lactentes e crianças de primeira infância e também a de produtos de puericultura correlatos. 2006b. Disponível em: http:// www.leidireto.com.br/lei-I I265.html. Acesso em: jun. 2020.

BRASIL. Legislação. Resolução $\mathbf{n}^{\circ}$. 64, de 16 de setembro de 2008. Aprova Regulamento técnico sobre atribuição de aditivos e seus limites máximos para alimentos. Disponível em: http://bvsms.saude.gov.br/bvs/saudelegis/anvisa/2008/ res0064_16_09_2008.html. Acesso em: jun. 2020. 
BRASIL. Legislação. Resolução RDC n. 163, de 17 de agosto de 2006. Aprova o documento sobre rotulagem nutricional de alimentos embalados (Complementação das Resoluções - RDC nº 359 e RDC nº. 360, de 23 de dezembro de 2003). 2006a. Disponível em: http://www.abima.com.br/dload/I3_68_resol_I63_06_leg_alim_nac.pdf. Acesso em: jun. 2020.

BRASIL. Ministério da Agricultura, Pecuária e Abastecimento. Regulamento de Inspeção Industrial e Sanitária de Produtos de Origem Animal - RIISPOA. Diário Oficial [da] República Federativa do Brasil, Brasília, DF, 27 mar. 2017 a.

BRASIL. Ministério da Agricultura, Pecuária e Abastecimento. Regulamento técnico para fixação de identidade e

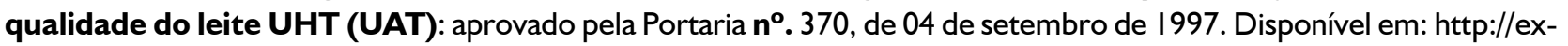
tranet.agricultura.gov.br/sislegisconsulta/consultarLegislacao.do?operacao=visualiz r\&id=1252. Acesso em: jun. 2020.

BRASIL. Ministério da Saúde. Agência Nacional de Vigilância Sanitária. Resolução RDC n 259 de 20 de setembro de 2002. Brasília: Ministério da saúde; 2002. Disponível em: http://www. anvisa.gov.br/alimentos/legis/especifica/ rotuali. htm. Acesso em: jun. 2020.

BRASIL. Ministério da Saúde. Agência Nacional de Vigilância Sanitária. Resolução RDC nº 360, de 23 de dezembro de 2003. Aprova o regulamento técnico sobre rotulagem nutricional de alimentos embalados, tornando obrigatória a rotulagem nutricional. 2003a. Disponível em: http:// www.anvisa.gov.br/legis/resol/2003/rdc/360_03rdc.htm. Acesso em: jun. 2020.

BRASIL. Ministério da Saúde. Agência Nacional de Vigilância Sanitária. Resolução RDC n . 429, de 8 de outubro de 2020. Dispõe sobre a rotulagem nutricional dos alimentos embalados. 2020b. Disponível em: https://www.in.gov.br/en/ web/dou/-/resolucao-de-diretoria-colegiada-rdc-n-429-de-8-de-outubro-de-2020-282070599. Acesso em: dez. 2020.

BRASIL. Ministério da Saúde. Agência Nacional de Vigilância Sanitária. Resolução RDC nº 359, de 23 de dezembro de 2003. Aprova o regulamento técnico de porções de alimentos embalados para fins de rotulagem nutricional. $2003 \mathrm{~b}$. Disponível em: http://www.itajuba.mg.gov.br/vias/leis/resolucao359.pdf. Acesso em: jun. 2020.

BRASIL. Ministério da Saúde. Agência Nacional de Vigilância Sanitária. RDC nº I36, de 08 de fevereiro de 2017. Estabelece os requisitos para declaração obrigatória da presença de lactose nos rótulos dos alimentos. 20I 7b. Disponível em: http://www.in.gov.br/materia/-/asset_publisher/Kujrw0TZC2Mb/content/id/20794620/dol-2017-02-09-resolucao-rdc-n-I 36-de-8-de-fevereiro-de-20I 7-20794494. Acesso em: jun. 2020.

BRASIL. Ministério da Saúde. Agência Nacional de Vigilância Sanitária. RDC nº 26, de 02 de julho de 20 I5. Dispõe sobre os requisitos para rotulagem obrigatória dos principais alimentos que causam alergias alimentares. Disponível em: http://www.agricultura.gov.br/assuntos/inspecao/produtos-vegetal/legislacao-I/biblioteca-de-normas-vinhos-e-bebidas/resolucao-rdc-no-26-de-2-de-julho-de-20I5.pdf/view. Acesso em: jun. 2020.

BRASIL. Ministério da Saúde. Portaria n. 27, de 13 de janeiro de 1998 . Aprova o regulamento técnico referente à informação nutricional complementar. Diário Oficial da União. Disponível em: http://www.abima.com.br/dload/I3_60_ port_27_98_leg_alim_nac.pdf. Acesso em: jun. 2020.

CAMARA, F. A.; WESCHENFELDER, S. Leite UHT integral: avaliação da rotulagem nutricional e dos padrões de identidade e qualidade. Revista do Instituto de Laticínios Cândido Tostes, v. 69, n. 4, p. 268-279, 2014.

CÂMARA, M. C. C.; MARINHO, C. L. C.; GUILAM; M. C. R. Análise crítica da rotulagem de alimentos diet e light no Brasil. Cadernos Saúde Coletiva, v. I6, n. I, p. 35-52, 2008.

COSTA, O. A. Avaliação de rótulos de embalagens de leites comercializados na região metropolitana de Fortaleza, Ceará. 2014. Nutrivisa - Revista de Nutrição e Vigilância em Saúde, Vol. I, n. I. Disponível em: http://www. revistanutrivisa.com.br/artigo-original/avaliacao-de-rotulos-de-embalagens-de-leites-comercializados-na-regiao-metropolitana-de-fortaleza ceara/. Acesso em: ago. 2020.

EMBRAPA. Árvore do Conhecimento Tecnologia de Alimentos. Rotulagem. Disponível em: http://www.agencia. cnptia.embrapa.br/gestor/tecnologia_de_alimentos/arvore/CONT000fid3s5b702wyiv80z4s473q90afwl.html. Acesso em: ago. 2020. 
GIBSON, Rosalind S. et al. Principles of nutritional assessment. Oxford university press, 1990. apud GIESEL, T. Análise de rotulagem de leite integral UHT comercializado no Distrito Federal. Brasília, 2009. 37f. Monografia (Especialização em Vigilância Sanitária e Controle de Qualidade de Alimentos). Universidade Castelo Branco, Brasília-DF, 2009.

INMETRO. Portaria nº I 57, de 19 de agosto de 2002. Aprova o Regulamento Técnico Metrológico estabelecendo a forma de expressar o conteúdo líquido a ser utilizado nos produtos pré-medidos. Disponível em: http://portal.anvisa. gov.br/wps/wcm/connect/e35e310047458b9I954dd53fbc4c6735/PORTARIA_INM

ETRO_157.pdf?MOD=AJPERES. Acesso em: jun. 2020.

MACHADO, S. S.; SANTOS, F. O.; ALBINATI, F. L.; SANTOS, L. P. R. Comportamento dos consumidores com relação à leitura e rótulo de produtos alimentícios. Alimentos e Nutrição, Araraquara, v. I7, n. I, p. 97 - $103,2006$.

MIYOSHI, L. Y. Rotulagem de leites UHT comercializados no varejo. Revista do Instituto de Laticínios Cândido Tostes, Juiz de Fora, v. 7I, n. I, p. 19-25, jan./mar., 2016.

MORAIS, W. S.; SILVA FILHO, C. R. M. Análise da rotulagem de leites UHT comercializados na cidade de Campina Grande estado da Paraíba, Brasil. Revista de Educação Continuada em Medicina Veterinária e Zootecnia do CRMV-SP, v. 14, n. 3, p. 65-65, 21 dez. 2016.

OLIVEIRA, K.B; KOBORI, C.N; RIQUEIRA, U. Avaliação da qualidade físico-química, rotulagem e ocorrência de adulterações em amostras de leite UHT. Revista do Instituto de Laticínios Cândido Tostes, Juiz de Fora, v. 74, n. 3, p. 195-206, jul./set., 2019.

PIERETTI, M. M.; CHUNG, D; PACENZA, R.; SLOTKIN, T.; SICHERER, S. H. Audit of manufactured products: Use of allergen advisory labels and identification of labeling ambiguities. Annals of Allergy, Asthma and Immunology. New York, NY. 2009. p. 337-34I.

TÉO, C.R.P.A. Intolerância à lactose: uma breve revisão para o cuidado nutricional. Arquivos de Ciências da Saúde Unipar, v.6, n.3, 2002. 